\title{
EARLY ALGEBRA NOS ANOS INICIAIS DO ENSINO FUNDAMENTAL: Manifestações do Pensamento Algébrico
}

\author{
Adriane Gaspari Ferreira ${ }^{1}$ \\ Diego Barboza Prestes ${ }^{2}$ \\ Magna Natalia Marin Pires ${ }^{3}$
}

\begin{abstract}
RESUMO
O objetivo principal deste artigo é analisar qualitativamente a produção escrita de estudantes do 2 o ano do Ensino Fundamental de uma escola pública da cidade de Londrina-PR, ao realizarem uma tarefa traduzida da Early Algebra em sala de aula, a fim de identificar possíveis manifestações do pensamento algébrico em suas produções. Para atender ao objetivo principal, utilizamos, em nossos procedimentos metodológicos, a Análise de Conteúdos de Bardin (2011). O resultado do estudo indica que os estudantes mostraram ser capazes de atribuir significados para as sequências de símbolos presentes na tarefa, pois traduziram informações representadas simbolicamente para outra forma de representação - a escrita -, que mobiliza a vertente representar do pensamento algébrico proposto por Ponte, Branco e Matos (2009). Simultaneamente à tradução das informações, os estudantes estabeleceram relações com fatos que acreditamos ser significativos para eles, mobilizando duas das características do pensamento algébrico apresentadas por Almeida e Santos (2017): construir significado e estabelecer relações. Tais constatações sugerem ser possível trabalhar com tarefas que podem propiciar uma introdução ao desenvolvimento do pensamento algébrico nos anos iniciais do Ensino Fundamental, o que, geralmente, não ocorre com a frequência esperada.
\end{abstract}

Palavras-chave: Educação matemática. Pensamento algébrico. Álgebra nos anos iniciais. Early Algebra.

\section{EARLY ALGEBRA IN THE INITIAL YEARS OF ELEMENTARY SCHOOL: MANIFESTATION OF ALGEBRAIC THINKING}

\section{ABSTRACT}

The main objective of this article is to qualitatively analyze the written production of students of the 2nd year of Elementary School from a public school in the city of Londrina-PR, by performing a task translated from Early Algebra in the classroom, in order to identify possible manifestations of thought algebraic in their productions. To meet the main objective we use in our methodological procedures the Content Analysis of Bardin (2011). The result of this study indicates that students were able to assign meanings to the sequences of symbols present in the task because they translated information represented symbolically to another form of representation, writing, that mobilizes the slope represent of the algebraic thought proposed by Ponte, Branco and Matos (2009). Simultaneously with the translation of information, students have established relationships with facts that we believe are meaningful to them, thus mobilizing two of the characteristics of algebraic thinking presented by Almeida and Santos (2017), building meaning and establishing relationships. These findings suggest that it is possible to work with tasks that can provide an introduction to the development of algebraic thinking in the early years of elementary school, which usually does not occur with the expected frequency.

Keywords: Mathematics Education. Algebraic thinking. Algebra in the early years. Early Algebra.

RECEBIDO EM: $18 / 4 / 2020$

ACEITO EM: 26/6/2020

\footnotetext{
1 Prefeitura de Londrina/PR. http://lattes.cnpq.br/2096616106439654. https://orcid.org/0000-0002-6095-1014.

2 Autor correspondente. Universidade Estadual de Londrina. Rodovia Celso Garcia Cid, PR-445, Km 380 - Campus Universitário. CEP 86057970. Londrina/PR, Brasil. http://lattes.cnpq.br/2544697726041740. https://orcid.org/0000-0003-0356-9166. diego_led@hotmail.com

3 Universidade Estadual de Londrina. http://lattes.cnpq.br/3345230466557782. https://orcid.org/0000-0001-6755-5674.
} 
O presente artigo promove uma reflexão a respeito do ensino de álgebra nos anos iniciais, mais especificamente do pensamento algébrico. As produções analisadas foram colhidas em uma turma de 20 ano do Ensino Fundamental conduzida pela primeira autora deste artigo, orientada pelo segundo e terceiro autores.

$O$ ensino da álgebra tem sido pesquisado e discutido por diversos autores (LINS; GIMENEZ, 2005; KAPUT; CARRAHER; BLANTON, 2008; KIERAN; YERUSHALMY, 2004; LINS; KAPUT, 2004), e o resultado de pesquisas realizadas por eles sinaliza que questões ligadas à álgebra deveriam estar presentes desde os primeiros anos da Educação Básica.

Para este trabalho utilizamos uma tarefa traduzida da Early Algebra. ${ }^{4}$ As tarefas da Early Algebra foram elaboradas por uma equipe que inclui psicólogos e educadores matemáticos que trabalham com professores e alunos desde 1985. As pesquisas que eles desenvolvem têm o objetivo de olhar com cuidado a forma como os alunos dos anos iniciais expressam relações gerais entre números e quantidades por meio de notação escrita, tabelas e diagramas. Eles veem a aritmética e a álgebra intimamente ligadas.

Após traduzir e adaptar algumas das tarefas elaboradas e disponibilizadas pela equipe indicada anteriormente, aplicamos uma sequência delas em uma turma de alunos do 2 o ano do Ensino Fundamental. Para este trabalho, são apresentadas produções de alunos ao realizarem uma das tarefas. A intenção é analisar as relações que as crianças estabelecem com os símbolos apresentados.

\section{DO TRABALHO COM ÁLGEBRA NA EDUCAÇÃO BÁSICA}

Grande parte dos estudantes que ingressa nos anos finais do Ensino Fundamental mostra algum tipo de dificuldade no desenvolvimento de tarefas que envolvem Álgebra. Esse fato pode estar relacionado com o modo mecânico de abordar o assunto, na maioria das vezes privilegiando a manipulação de símbolos e a memorização de regras em detrimento do raciocínio algébrico e do real significado das operações. Outro ponto que pode exercer relação é o fato de que geralmente os estudantes dos anos iniciais do Ensino Fundamental não têm contato algum com tarefas que viabilizem o desenvolvimento de habilidades que promovam o pensamento algébrico, mesmo que documentos oficiais vigentes em todo o território nacional, como a Base Nacional Comum Curricular (BRASIL, 2017), indiquem o trabalho com a unidade temática Álgebra em todo o período que compõe os anos iniciais do Ensino Fundamental.

Em âmbito nacional, existe um documento ${ }^{5}$ voltado para o primeiro ciclo de alfabetização que apresenta o pensamento algébrico como um dos eixos estruturantes para a alfabetização e letramento matemático. Este documento traz, entre outras informações, os direitos de aprendizagem dos estudantes deste ciclo no que se refere à dis-

\footnotetext{
Termo em inglês utilizado para designar "início da álgebra" ou "álgebra precoce". Mais informações a respeito da Early Algebra podem ser obtidas em: http://ase.tufts.edu/education/earlyalgebra/team.asp. Acesso em: 15 abr. 2019.

5 Elementos conceituais e metodológicos para definição dos direitos de aprendizagem e desenvolvimento do ciclo de alfabetização (1으, 2으 e 3 ㅇanos) do Ensino Fundamental.
} 
ciplina de Matemática e, com relação ao eixo pensamento algébrico, determina alguns objetivos de aprendizagem, sendo necessário no 1 을 ano introduzir, no 2 은 introduzir e aprofundar e no 3ㅇa aprofundar e consolidar. A saber:

- Estabelecer critérios para agrupar, classificar e ordenar objetos, considerando diferentes atributos.

- Reconhecer padrões de uma seqüência para identificação dos próximos elementos, em seqüências de sons e formas ou padrões numéricos simples. • Produzir padrões em faixas decorativas, em seqüências de sons e formas ou padrões numéricos simples (BRASIL, 2012, p. 77).

Por meio deste documento é possível observar a preocupação com a necessidade do estudo de Álgebra já nos anos iniciais do Ensino Fundamental, mesmo que de maneira intuitiva, sem que, necessariamente, os alunos possuam domínio da linguagem algébrica. Dessa forma, acreditamos que é necessário oportunizar aos estudantes dos anos iniciais, experiências com noções algébricas de maneira informal e em articulação com os conceitos de aritmética.

Concordamos com Caldeira $(2010$, p. 37) quando esta relata que

[...] as orientações curriculares acerca da álgebra na educação têm reconhecido seu papel central na matemática escolar e proposto caminhos para uma mudança desse cenário, no sentido de possibilitar aos alunos da escola básica o desenvolvimento de certas habilidades necessárias ao trabalho com a álgebra.

Pimentel e Vale (2009) ressaltam que seria interessante uma abordagem introdutória nesse grau de ensino. Boni e Savioli (2015) corroboram essa ideia e sugerem a introdução ao pensamento algébrico nos anos iniciais, porque, desse modo, os estudantes não teriam tantas dificuldades com a Álgebra em anos posteriores e poderiam atribuir algum significado à Álgebra simbólica, encarando-a como uma extensão dos estudos anteriores.

Um aspecto que pode influenciar na introdução de um trabalho voltado ao desenvolvimento do pensamento algébrico dos estudantes nos anos iniciais do Ensino Fundamental, é a falta de conhecimento ou a insegurança dos professores desse nível de ensino com relação à Matemática como um todo, o que, muitas vezes, os leva a privilegiar o trabalho com outras disciplinas. De acordo com Curi (2004, p. 76-77),

[...] é possível considerar que os futuros professores [dos anos iniciais] concluem cursos de formação sem conhecimentos de conteúdos matemáticos com os quais irão trabalhar, tanto no que concerne a conceitos quanto a procedimentos, como também da própria linguagem matemática que utilizarão em sua prática docente. Em outras palavras, parece haver uma concepção dominante de que o professor polivalente não precisa "saber Matemática" e que basta saber como ensiná-la.

Entendemos, entretanto, que não é necessário que os professores dos anos iniciais tenham um conhecimento aprofundado em Matemática para realizar um trabalho relacionado à introdução do pensamento algébrico. 


\section{DO PENSAMENTO ALGÉBRICO}

De acordo com nossos estudos, parece não haver um consenso que estabeleça uma definição do que realmente seja o pensamento algébrico; por isso apresentamos caracterizações desse tipo de pensamento segundo alguns autores.

Kieran (2004, p. 149, tradução nossa) afirma que o pensamento algébrico nos primeiros anos de escolaridade

[...] envolve o desenvolvimento de modos de pensar por meio de atividades para as quais o simbolismo da álgebra pode ser usado como ferramenta, mas que não são exclusivas da álgebra e que podem ser abordadas sem qualquer uso de simbolismo algébrico, tais como analisar relações entre quantidades, observar a estrutura, generalizar, resolver problemas, justificar, provar e prever.

Os elementos que caracterizam o pensamento algébrico, elencados por Fiorentini, Miorim e Miguel (1993, p. 87), são: "percepção de regularidades, percepção de aspectos invariantes em contraste com outros que variam, tentativas de expressar ou explicitar a estrutura de uma situação-problema e a presença do processo de generalização."

Booker (2009 apud SILVA; SAVIOLI; PASSOS, 2015, p. 124) menciona o pensamento algébrico como sendo um "meio de lidar com generalizações e maneiras de pensar, que permitam que resultados sejam expressos por meio de uma variedade de formas de problemas mais simples do que os que encontram uma resposta particular".

Almeida e Santos (2017, p. 53) acreditam que o pensar algebricamente pode ser caracterizado por intermédio de cinco características: "estabelecer relações", "generalizar", "modelar", "operar com o desconhecido" e "construir significado". Esses autores afirmam que tais características comunicam-se e se inter-relacionam de modo a ocorrerem concomitantemente, cada uma levando ao desenvolvimento da outra, sem que haja uma ordem preestabelecida, como ilustra a Figura 1. Reiteram, porém, que a capacidade de estabelecer relações ocupa posição central no pensamento algébrico, pois, segundo eles, "um sujeito só está pensando algebricamente se conseguir estabelecer relações" (ALMEIDA; SANTOS, 2017, p. 58).

Figura 1 - Esquema das características do pensamento algébrico

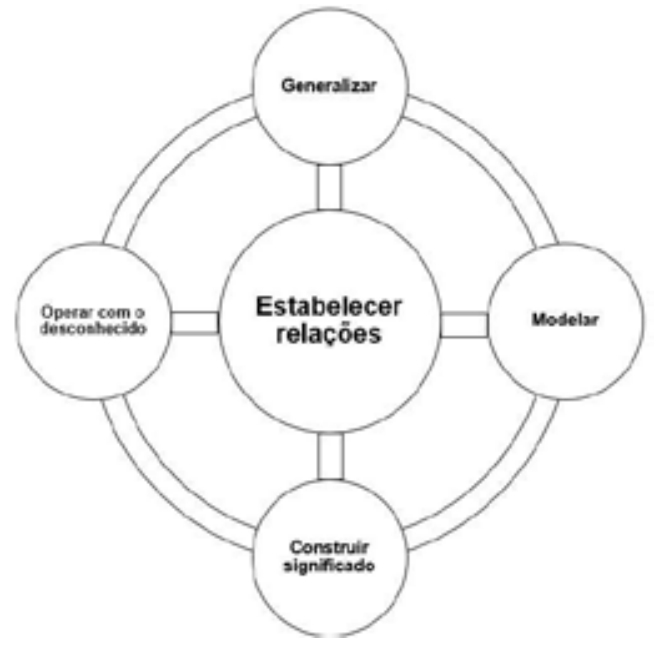

Fonte: ALMEIDA; SANTOS (2017, p. 54).

Contexto \& Educação

Editora Unijuí •ISSN 2179-1309 • Ano 36・no 113・Jan./Abr. 2021 
Ponte, Branco e Matos (2009) utilizam mais de uma característica para estabelecer suas concepções acerca do pensamento algébrico, sendo esta constituída por três vertentes (Quadro 1): o representar, o raciocinar e o resolver problemas,

[...] representar (em relação à capacidade dos estudantes em utilizar diferentes representações com caracteres de natureza simbólica), raciocinar (tanto dedutivamente quanto intuitivamente tem grande importância o relacionar e o generalizar) e resolver problemas (que trata da utilização de elementos algébricos para interpretar e resolver problemas matemáticos ou não, incluindo modelar situações) (PONTE; BRANCO; MATOS, 2009, p. 10).

Quadro 1 - Vertentes fundamentais do pensamento algébrico

\begin{tabular}{|c|c|c|}
\hline & - $\begin{array}{l}\text { Ler, compreender, escrever e operar com símbolos usando as } \\
\text { convenções algébricas usuais; }\end{array}$ \\
Representar & $\begin{array}{l}\text { Traduzir informação representada simbolicamente para outras } \\
\text { formas de representação (por objetos, verbal, numérica, tabelas, } \\
\text { gráficos) e vice-versa; }\end{array}$ \\
& $\begin{array}{l}\text { Evidenciar sentido de símbolo, nomeadamente interpretando os } \\
\text { diferentes sentidos no mesmo símbolo em diferentes contextos. }\end{array}$ \\
\hline Raciocinar & $\begin{array}{l}\text { Relacionar (em particular, analisar propriedades); } \\
\text { Generalizar e agir sobre essas generalizações revelando } \\
\text { compreensão das regras; } \\
\text { Resolver } \\
\text { problemas e } \\
\text { modelar situações }\end{array}$ & $\begin{array}{l}\text { Usar expressões algébricas, equações, inequações, sistemas (de } \\
\text { equações e de inequações), funções e gráficos na interpretação } \\
\text { e resolução de problemas matemáticos e de outros domínios } \\
\text { (modelação). }\end{array}$ \\
\hline
\end{tabular}

Fonte: PONTE; BRANCO; MATOS (2009, p. 11).

A partir dessas caracterizações do pensamento algébrico, é plausível afirmar que pensar algebricamente pode envolver o entrelaçamento de mais de um tipo de raciocínio e, em grande parte das situações, os raciocínios não são desenvolvidos pelos estudantes de forma isolada; pelo contrário, um acaba levando ao desenvolvimento de outros.

\section{DA APLICAÇÃO DA TAREFA}

O trabalho foi iniciado no final do primeiro semestre do ano de 2017, mas, alguns meses antes dessa data, uma tarefa similar fora desenvolvida com esses mesmos estudantes. No dia da aplicação da tarefa, após a realização das atividades de rotina da turma, foi proposta aos estudantes do 20 ano do Ensino Fundamental de uma escola pública do município de Londrina-PR, a execução de uma tarefa, cujo objetivo, segundo a perspectiva da Early Algebra, era introduzir símbolos como meio de comunicação. Nesse dia estavam presentes 17 dos 23 estudantes matriculados na turma.

A primeira autora deste artigo, professora titular da turma, explicou aos estudantes as principais características da tarefa, que era baseada na formação de uma frase relacionada aos símbolos apresentados em sequência. Para isso, utilizou a lousa para desenhar uma sequência de símbolos, conforme mostra a Figura 2. 
Figura 2 - Representação dos símbolos desenhados na lousa pela professora

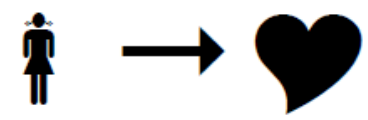

Fonte: Os autores.

A professora questionou os estudantes a respeito do que aquela sequência de símbolos representava para eles. Muitos deram suas contribuições com frases como:

- A menina está apaixonada.

- A menina encontrou o amor.

- A menina está amando.

Nesse momento, a professora informou-lhes que não havia uma única frase considerada correta para traduzir aquela sequência de símbolos, e que cada um poderia dar uma interpretação diferente que poderia estar correta. De acordo com as indicações da Early Algebra, é importante conversar abertamente com os estudantes sobre as ambiguidades dos símbolos, deixando-os cientes de que, muitas vezes, não há uma única intepretação considerada correta.

Alguns lembraram-se da tarefa realizada anteriormente, o que nos permite pensar que, de algum modo, ela pode ter sido significativa e marcante para esses estudantes, pois foi uma das primeiras oportunidades no ano em que se teve a possibilidade de trabalhar com um tipo de produção espontânea dos estudantes.

Depois dessa conversa inicial, a professora entregou a tarefa (Figura 3) impressa em uma folha separada para cada estudante, orientando-os a realizá-la sem consultar os colegas, pois cada um deveria escrever a sua interpretação da sequência de símbolos.

Figura 3 - Tarefa trabalhada com a turma

\begin{tabular}{|c|c|}
\hline SIMBOLOS & UMA POSSIBILIDADE DE INTERPRETAÇÃO \\
\hline JOANA & \\
\hline$\dot{\mathbb{P}} \equiv \hat{\boldsymbol{t}}$ & \\
\hline CAIO MARIA & \\
\hline (1) DDd (;) & \\
\hline † ( & \\
\hline sUZI & \\
\hline $8-2+5$ & \\
\hline 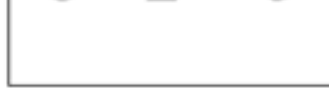 & \\
\hline
\end{tabular}

Fonte: Adaptada da Early Algebra. 
A maioria dos estudantes não mostrou dificuldades na interpretação dos símbolos, talvez pelo fato de já terem tido contato com outra tarefa de estrutura semelhante. Houve, porém, aqueles que questionaram o significado de certos símbolos, que, possivelmente, não lhes eram usuais. Para não interferir em seus raciocínios e não resolver o item para eles, a professora indicava que escrevessem o significado que eles imaginavam ser o mais adequado para a situação. Alguns estudantes ainda necessitaram de auxílio na transcrição de seu raciocínio, por não estarem totalmente alfabetizados. Por esse motivo, a professora titular e a professora auxiliar, que a acompanhava nesse dia, ajudaram tais estudantes na ortografia de determinadas palavras, mas sem interferir em seus raciocínios.

De modo geral, a realização da atividade transcorreu como esperado, e até mesmo os estudantes com mais dificuldades esforçaram-se para finalizar a tarefa. A maior parte deles terminou a tarefa no período de tempo previsto. Apenas três estudantes necessitaram de mais tempo e mais auxílio para a conclusão da tarefa, mas conseguiram finalizar.

\section{DOS RESULTADOS OBTIDOS}

Neste artigo, que traz uma argumentação qualitativa de cunho interpretativo, à luz da Análise de Conteúdo de Bardin (2011), optamos discutir, por conveniência, a produção escrita dos estudantes relacionada à segunda sequência de símbolos, tentando compreender o porquê dos registros e o contexto no qual ocorreu o desenvolvimento desse item da tarefa. A escolha de tal sequência ocorreu porque esse foi o item que gerou mais dúvidas entre os estudantes e por ser a sequência que apresentou a maior diversidade nas interpretações, fato que identificamos após realizarmos uma espécie de leitura flutuante, como indicado por Bardin (2011).

Depois de ler as produções de todos os estudantes e selecionar os itens a serem analisados, criamos agrupamentos segundo características de semelhanças da produção escrita (Quadro 2), a fim de obter um parâmetro comum para que as inferências fossem feitas. Atribuímos às produções os códigos que variam de E1 até E17. A letra E significa estudante e os numerais indicam a ordem em que as tarefas foram digitalizadas para o estudo.

Quadro 2 - Agrupamento das produções relacionadas à segunda sequência de símbolos

\begin{tabular}{|c|l|}
\hline Caio e/ou Maria & E4; E7; E9; E10; E11; E13; E15; E16 \\
\hline Menina e/ou Menino & E1; E8; E12; E14; E17 \\
\hline Eu & E6; E8 \\
\hline Outros & E2; E3; E5 \\
\hline
\end{tabular}

Fonte: Os autores.

Identificamos três grupos com características semelhantes: dos estudantes que registraram o nome de Caio, Maria ou de ambos, dos que registraram menina, menino ou ambos e dos estudantes que escreveram utilizando a primeira pessoa do singular (Eu). Criamos também o agrupamento denominado "Outros", para incluir as produções escritas que não possuem características presentes nos três agrupamentos citados anteriormente. 
A produção escrita do estudante identificado por E8 (Figura 4) tinha características de dois dos agrupamentos, por isso registramos o código de identificação desse estudante no agrupamento "Eu" e no de "Menina e/ou Menino".

Figura 4 - Produção do estudante E8

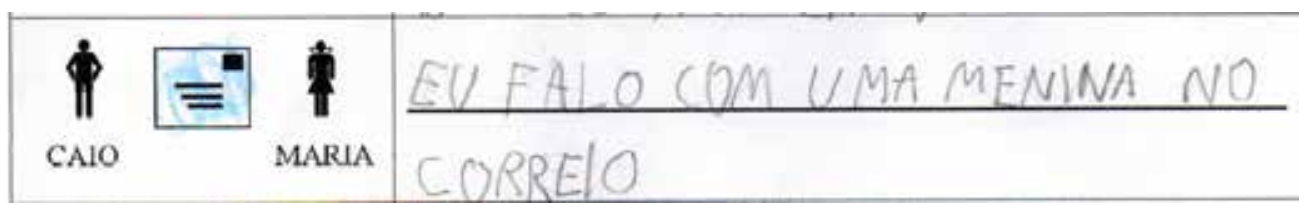

Fonte: Produção dos estudantes.

O estudante E8 construiu uma frase na primeira pessoa do singular, característica das produções escritas do agrupamento nomeado "Eu", e também registrou a palavra MENINA, característica das produções do agrupamento intitulado "Menina e/ou Menino".

Para nos referir às produções de cada um dos quatro agrupamentos e fazer inferências, optamos por mostrar uma produção de cada um deles. Desse modo, escolhemos a produção do estudante E10 (Figura 5) para representar o agrupamento "Caio e/ ou Maria".

Figura 5 - Produção do estudante E10

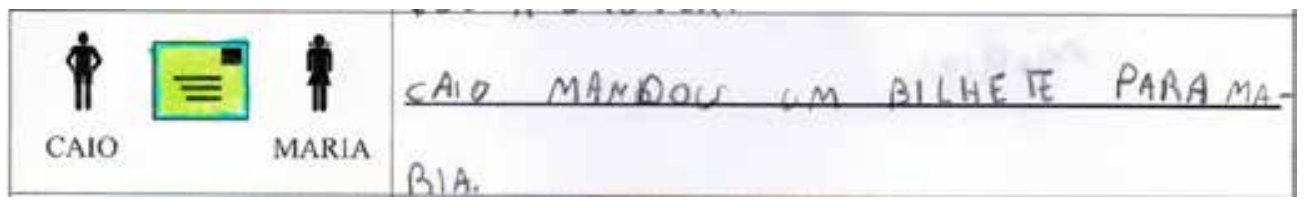

Fonte: Produção dos estudantes.

Os estudantes desse agrupamento exploraram tanto a sequência de símbolos quanto suas legendas ao registrarem o(s) nome(s) indicado(s), mesmo não sendo obrigatório, o que pode indicar certa capacidade de relacionar e organizar informações. Independentemente do significado dado ao símbolo central da sequência, que alguns estudantes desse agrupamento interpretaram como sendo bilhete, carta, convite, currículo ou passaporte, o fato é que todos eles foram capazes de construir uma frase relacionando elementos da sequência de símbolos de acordo com o que julgaram conveniente para a situação. No caso específico do estudante E10, podemos inferir que ele reconheceu o símbolo central como sendo um envelope, um ícone de envio de mensagens presente em meios digitais ou algo utilizado para enviar informações, e, de acordo com a posição dos elementos e possivelmente por realizarmos leituras da esquerda para direita, afirmou que Caio fez o envio para Maria.

Escolhemos a produção do estudante E12 (Figura 6) para representar o agrupamento "Menina e/ou Menino".

Figura 6 - Produção do estudante E12

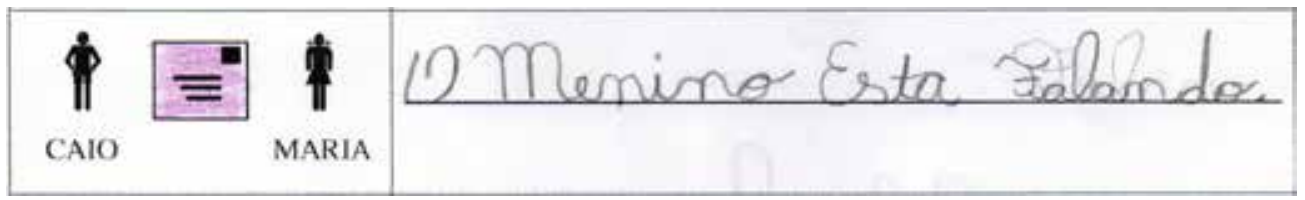

Fonte: Produção dos estudantes. 
Os estudantes desse agrupamento não utilizaram todas as informações presentes na sequência de símbolos em suas produções, pois não registraram os substantivos Caio e Maria, o que não podemos considerar como erro ou acerto. Esses estudantes mostraram, contudo, reconhecer a presença dos símbolos que indicam masculino e/ou feminino ao registrar menino e/ou menina em suas produções. No caso do estudante E12, é possível afirmar que ele reconheceu a presença do símbolo que indica masculino e entendeu o símbolo central da sequência como um elemento de comunicação. Como não era obrigatória a utilização de todos os símbolos para a descrição da sequência, podemos constatar que o estudante E12 fez uma interpretação satisfatória.

Segue a produção do estudante E6 (Figura 7) para representar o agrupamento "Eu".

Figura 7 - Produção do estudante E6

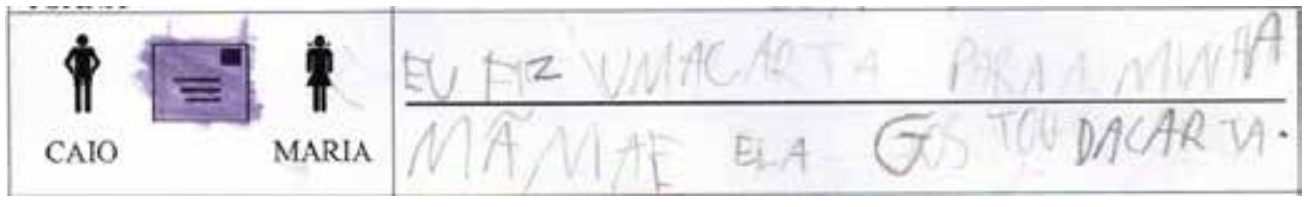

Fonte: Produção dos estudantes.

Os estudantes desse agrupamento sentiram-se representados pelo símbolo que indica o indivíduo masculino nomeado por Caio, talvez por serem meninos, por quererem ser reconhecidos como Caio ou simplesmente para atenderem ao enunciado da tarefa e dar uma possível interpretação para a sequência de símbolos. Eles construíram uma frase interpretando o símbolo central como algo relacionado à comunicação, além de reconhecerem o símbolo que indica feminino, nomeado de Maria. A produção do estudante E6, mesmo com desvio ortográfico, sugere a frase: "Eu fiz uma carta para a minha mamãe e ela gostou da carta". Essa interpretação pode ter se dado pelo fato de a mãe desse estudante se chamar Maria, ou por sua mãe ser, para ele, a representação de um indivíduo feminino, o que nos leva a inferir que ele pode ter uma relação próxima com sua mãe ou que gostaria de ter.

A produção do estudante E3 (Figura 8) foi a escolhida para representar o agrupamento "Outros".

Figura 8 - Produção do estudante E3

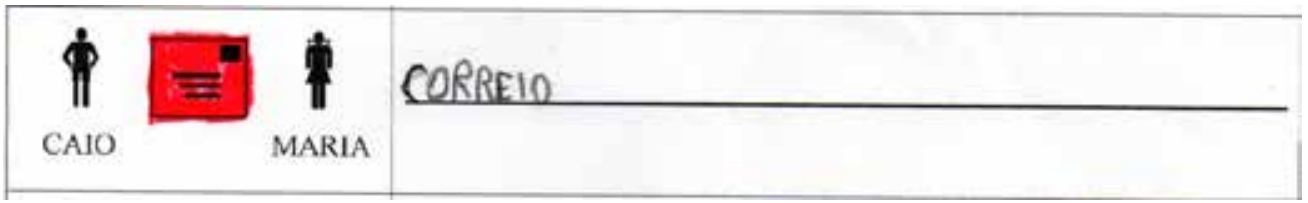

Fonte: Produção dos estudantes.

Uma característica marcante dos estudantes desse agrupamento é que a interpretação da sequência de símbolos é composta por apenas um vocábulo além de "correio"; as demais interpretações foram "protestando" e "estudando". Isso pode ter ocorrido em razão da dificuldade desses estudantes em formar uma frase a partir de símbolos ou pela dificuldade de registrar por escrito certas palavras, uma vez que cursavam o 20 ano do Ensino Fundamental. Possivelmente esses estudantes utilizaram apenas o símbolo 
central da sequência para fazer suas interpretações, porque suas produções não fazem menção aos símbolos das extremidades da sequência. O estudante E3 provavelmente associou o símbolo central a um envelope, ou pacote postal, que, no Brasil, geralmente é encaminhado às agências dos Correios para que seja enviado ao destinatário; isso pode ter ocorrido por esse estudante ter algum contato com esse tipo de situação em seu cotidiano.

\section{CONSIDERAÇÕES}

Neste artigo apresentamos uma análise qualitativa da produção escrita dos estudantes do 20 ano do Ensino Fundamental a respeito de um item de uma tarefa traduzida da Early Algebra, com o objetivo de evidenciar manifestações características do pensamento algébrico de estudantes dessa faixa etária, mostrando uma possível viabilidade de trabalho com tarefas que podem propiciar uma introdução ao desenvolvimento do pensamento algébrico nos anos iniciais do Ensino Fundamental.

De modo geral, nas produções escritas desses estudantes estão presentes indícios de características do pensamento algébrico, mesmo sem eles terem conhecimento formal da linguagem algébrica. Essa afirmação baseia-se no fato de eles terem sido capazes de traduzir as informações contidas nas sequências de símbolos para a língua materna, apresentando significados plausíveis para cada uma das sentenças estudadas. Assim, mobilizam a vertente representar, do pensamento algébrico proposto por Ponte, Branco e Matos (2009, p. 11), porque, para esses autores, representar envolve o "traduzir informação representada simbolicamente para outras formas de representação (por objetos, verbal, numérica, tabelas, gráficos) e vice-versa". Utilizando-se dessa "tradução", os estudantes demonstraram ser capazes de atribuir significados para as sequências de símbolos e, ao mesmo tempo, estabeleceram relações com fatos que acreditamos significativos para eles, mobilizando, assim, duas das características do pensamento algébrico propostas por Almeida e Santos (2017): construir significado e estabelecer relações.

Uma das maiores dificuldades dos estudantes não estava essencialmente em interpretar a sequência de símbolos de cada item e dar a ela algum significado, mas em transcrever seu raciocínio para a linguagem verbal. Em determinadas produções escritas é possível identificar palavras com desvio de ortografia; isso está diretamente relacionado com o fato de as produções serem de estudantes do 2음 ano do Ensino Fundamental que ainda estão em processo de alfabetização. Outro aspecto que deve ser considerado é que o desenvolvimento da tarefa valorizou a produção espontânea dos discentes, levando-os a explorar seu repertório e, consequentemente, a escrever palavras não rotineiras em seu vocabulário.

Acreditamos que o fato de esses estudantes já terem tido contato com tarefas semelhantes à apresentada, pode ter influenciado positivamente no resultado, pois eles aparentaram certa segurança durante o desenvolvimento de uma tarefa que exige tomada de decisão, mesmo estando ainda em processo de alfabetização. Isso reforça a ideia de que um trabalho, com tarefas que propiciem uma introdução ao pensamento algébrico, pode ser amplamente explorado desde os anos iniciais do Ensino Fundamental, assim como indicam Pimentel e Vale (2009) e Boni e Savioli (2015). 
Embora a professora que aplicou essa tarefa (titular da turma) seja licenciada em Matemática, julgamos não ser necessária tal formação para desenvolver esse trabalho com estudantes desse nível de ensino, pois, como foi possível verificar no decorrer deste artigo, as tarefas não exigem um conhecimento matemático aprofundado.

Entendemos que não é necessário que os professores dos anos iniciais tenham um extenso conhecimento matemático para que realizem um trabalho envolvendo pensamento algébrico nos anos iniciais, mas que passem a ter o hábito de aplicar tarefas que possibilitem o desenvolvimento de habilidades que propiciem o pensamento algébrico já nos anos iniciais do Ensino Fundamental, de modo a capacitá-los para o estudo formal dos conceitos de Álgebra que, certamente, serão abordados futuramente.

\section{REFERÊNCIAS}

ALMEIDA, Jadilson Ramos de; SANTOS, Marcelo Câmara dos. Pensamento algébrico em busca de uma definição. Revista Paranaense de Educação Matemática, Campo Mourão, PR, v. 6, n. 10, p. 34-60, jan./ jun. 2017.

BARDIN, Laurence. Análise de conteúdo. Trad. Luís Antero Reto e Augusto Pinheiro. São Paulo: Edição 70, 2011.

BONI, Keila Tatiana; SAVIOLI, Angela Marta Pereira das Dores. Contribuições para o desenvolvimento do pensamento algébrico. Perspectivas da Educação Matemática, Campo Grande, MS, v. 8, n. 17, p. 265-285, 2015.

BRASIL. Ministério da Educação. Elementos conceituais e metodológicos para definição dos direitos de aprendizagem e desenvolvimento do ciclo de alfabetização (1ㅇ, 2 e 3ㅇ anos) do Ensino Fundamental. Brasília: MEC; SEB, 2012.

BRASIL. Ministério da Educação. Base Nacional Comum Curricular: versão final. Brasília, DF, 2017.

CALDEIRA, Janaina Soler. Um estudo sobre o pensamento algébrico em uma comunidade de prática de formação de professores de matemática. 2010. 127 f. Dissertação (Mestrado em Ensino de Ciências e Educação Matemática) - Universidade Estadual de Londrina, Londrina, 2010.

CURI, Edda. Formação de professores polivalentes: uma análise de conhecimentos para ensinar Matemática e de crenças e atitudes que interferem na constituição desses conhecimentos. 2004. 278 f. Tese (Doutorado em Educação Matemática) - Pontifícia Universidade Católica de São Paulo, São Paulo, 2004. FIORENTINI, Dario; MIORIM, Maria Ângela; MIGUEL, Antonio. Contribuição para um repensar... a educação algébrica elementar. Pro-Posições, v. 4, n. 1, p. 78-91, 1993.

KAPUT, James; CARRAHER, David William; BLANTON, Maria. Algebra in the Early Grades. New York: Lawrence Erlbaum Associates, 2008.

KIERAN, Carolyn. Algebraic thinking in the early grades: What is it? The Mathematics Educator, v. 8, n. 1 , p. 139-151, 2004.

KIERAN, Carolyn; YERUSHALMY, Michal. Research on the role of technology environments in algebra learning and teaching. In: STACEY, Kaye; CHICK, Helen; KENDAL, Margaret (ed.). The Future of Teaching and Learning of Algebra. The $12^{\text {th }}$ ICMI Study. Boston: Kluwer, 2004. p. 99-152.

LINS, Romulo Campos; KAPUT, James. The early development of algebraic reasoning: The current state of the field. In: STACEY, Kaye; CHICK, Helen; KENDAL, Margaret (ed.). The Future of Teaching and Learning of Algebra. The $12^{\text {th }}$ ICMI Study. Boston: Kluwer, 2004. p. 73-96.

LINS, Romulo Campos; GIMENEZ, Joaquim. Perspectivas em aritmética e álgebra para o século XXI. 7. ed. Campinas: Papirus, 2005.

PIMENTEL, Teresa; VALE, Isabel. A descoberta de padrões no desenvolvimento do cálculo mental: uma experiência com professores do 10 ciclo. In: ENCONTRO DE INVESTIGAÇÃO EM EDUCAÇÃO MATEMÁTICA (EIEM), 19., 2009, Vila Real. Anais [...]. Vila Real, 2009.

PONTE, João Pedro da; BRANCO, Neusa; MATOS, Ana. Álgebra no ensino básico. Lisboa: ME - DGIDC, 2009.

SILVA, Daniele Peres da; SAVIOLI, Angela Marta Pereira das Dores; PASSOS, Marinez Meneghello. Caracterizações do pensamento algébrico manifestadas por estudantes em uma tarefa da Early Algebra. Revista Brasileira de Ensino de Ciência e Tecnologia. v. 8, n. 3, p. 104-134, maio/ago. 2015. 